\title{
DOPO-VTS-based coatings in the realm of fire retardants for cotton textile
}

Chernyy, Sergey; Ullah, Saif; Sørensen, Gitte; Tordrup, Sie Woldum; Bøgh Pedersen, Peter; Almdal, Kristoffer

Published in:

Journal of Applied Polymer Science

Link to article, DOI:

10.1002/APP.41955

Publication date:

2015

Document Version

Peer reviewed version

Link back to DTU Orbit

Citation (APA):

Chernyy, S., Ullah, S., Sørensen, G., Tordrup, S. W., Bøgh Pedersen, P., \& Almdal, K. (2015). DOPO-VTSbased coatings in the realm of fire retardants for cotton textile. Journal of Applied Polymer Science, 132(19), [41955]. https://doi.org/10.1002/APP.41955

\section{General rights}

Copyright and moral rights for the publications made accessible in the public portal are retained by the authors and/or other copyright owners and it is a condition of accessing publications that users recognise and abide by the legal requirements associated with these rights.

- Users may download and print one copy of any publication from the public portal for the purpose of private study or research.

- You may not further distribute the material or use it for any profit-making activity or commercial gain

- You may freely distribute the URL identifying the publication in the public portal 


\title{
DOPO-VTS Based Coatings in the Realm of Fire Retardants for Cotton Textile
}

\author{
Sergey Chernyy, ${ }^{1}$ Saif Ulah, ${ }^{1}$ Gitte Sørensen, ${ }^{2}$ Sie Woldum Tordrup, ${ }^{2}$ Peter Bøgh Pedersen, ${ }^{2}$ \\ Kristoffer Almdal ${ }^{1}$ \\ ${ }^{1}$ Technical University of Denmark, DTU Nanotech - Department of Micro- and Nanotechnology, \\ Produktionstorvet, bldg. 423, 2800 Kgs. Lyngby, Denmark \\ ${ }^{2}$ Danish Technological Institute, Aarhus, Teknologiparken, Kongsvang Allé 29, 8000 Aarhus, \\ Denmark
}

\section{Corresponding Author:}

Sergey Chernyy

Email: sech@nanotech.dtu.dk 


\begin{abstract}
The work elucidates the feasibility of incorporation of phosphorus-silicon containing fire retardant (10-(2-trimethoxysilyl-ethyl)-9-hydro-9-oxa-10-phosphaphenanthrene-10-oxide [DOPOVTS]) into nanosol coating solutions by co-hydrolysis co-condensation reaction of DOPO-VTS with tetraethoxysilane precursor (TEOS). Impregnation of cotton with the organophosphorus silane in a form of nanosol dispersion afforded better fire retardancy of such samples compared to pure DOPO or TEOS treated cotton indicating synergism between phosphorus and silicon containing species in a condensed phase. The detailed analysis by TGA-MS and SEM pointed to the fact that DOPO-VTS acts as a promoter of cotton degradation which, in turn, results in acceleration of the charring process and formation of compact char in contrast to TEOS treated samples. Further analysis of the char by XPS confirmed high content of carbonaceous residue in the case of DOPOVTS treated samples while mainly siliceous component was left in the char in case of cotton treated with TEOS. Standard flammability test (EN ISO 15025:2008) additionally confirmed the absence of smoldering and better overall fire performance of the DOPO-VTS samples in contrast to TEOS treated samples.
\end{abstract}

\title{
1. Introduction
}

Most textile materials such as fabrics and carpets are made up of natural and synthetic polymeric fibers or sometimes a blend of both. The synthetic (e.g. nylon) and natural polymers (e.g. cellulose) are flammable and there is a necessity to incorporate fire retardants into textile materials in order to assure human safety under several circumstances. ${ }^{1}$ Cotton containing $90 \%$ of cellulose is the most valuable and commonly used fiber for textile fabrics. The reason for this is its high tensile strength, good abrasion resistance, high moisture absorbance, high dye-ability and high alkali-resistance. ${ }^{2}$ 
Apart from numerous advantages cotton cellulose fibers have some inherent disadvantages, for example, high flammability, low thermal stability, easiness for ignition and rapid combustion. ${ }^{3}$

Thermal decomposition and burning behavior of cellulosic materials as a result of fire is a complex process. The first step in the fire process is endothermic pyrolysis followed by exothermic combustion. The main products of cellulose decomposition are inert gases $\left(\mathrm{CO}_{2}\right.$ and $\left.\mathrm{H}_{2} \mathrm{O}\right)$, combustible volatiles (tar) and char residue. It is generally accepted that the higher the fraction of char the lower would be the mass fraction of combustible volatiles and vice versa.

Applying coatings containing silicon, nitrogen and phosphorus elements could retard thermal degradation and change burning behavior of the textile materials. The mechanism of action of such coatings involves the release of nonflammable gases $\left(\mathrm{NH}_{3}, \mathrm{~N}_{2}, \mathrm{H}_{2} \mathrm{O}, \mathrm{CO}_{2}\right)$ from, for instance, polyurea, melamine, ammonium polyphosphate $\left[\left(\mathrm{NH}_{4} \mathrm{PO}_{3}\right)_{n}\right]$, di-ammonium hydrogen phosphate [( $\left.\left(\mathrm{NH}_{4}\right)_{2} \mathrm{HPO}_{4}\right]$, alumina trihydrate $\left(\mathrm{Al}_{2} \mathrm{O}_{3} \cdot{ }_{3} \mathrm{H}_{2} \mathrm{O}\right)$ and calcium carbonate $\left(\mathrm{CaCO}_{3}\right)$ containing coatings. In the case of phosphorus containing coatings the formation of polyphosphoric acid (PPA) was reported to occur above $300{ }^{\circ} \mathrm{C}$ which is followed by dehydration of the PPA to the phosphorus pentoxide $\left(\mathrm{P}_{2} \mathrm{O}_{5}\right)$ at temperature higher than $450{ }^{\circ} \mathrm{C} .{ }^{4,5}$ High activity of the $\mathrm{P}_{2} \mathrm{O}_{5}$ leads to numerous dehydration and phosphorylation reactions occurring within the material, which in turn results in the formation of the cross-linked char layer. The char layer is thermally stable and efficiently prevents the diffusion of oxygen into the material as well as the diffusion of the flammable gasses out of the material thereby precluding further flame propagation. It is also possible to combine two of the methods outlined above by incorporating a nonflammable gas releasing agent, e.g. melamine, and a crosslinking agent, e.g. APP, into the same compound (i.e. melamine-polyphosphate). This approach results in the formation of the so-called intumescent type of fire retardant coatings. Upon their thermal degradation, the inert gases expand the char layer imparting it with lower heat conductivity and gas permeability. However, many requirements are to be met by a concrete fire 
retardant formulation in order to function via the intumescent mechanism. Upon degradation of the material the foaming may not occur if the viscosity of the melt is too high or too low. ${ }^{6}$

Nanosol coatings can alternatively be used to retard the thermal degradation of cellulosic textile materials. The inherently inflammable silicon oxide based matrix of the nanosol coatings results in the formation of the inorganic layer on the surface of the material which is thermally stable up to $1000{ }^{\circ} \mathrm{C}$. In this regard, some state-of-the-art flame retardant coatings were developed which are based only on silica or pure tetraethoxysilane coatings produced by plasma-assisted deposition. ${ }^{7-9}$ Moreover, "doping” of the silica composed coatings with nitrogen, phosphorus and alumina containing compounds were found to be advantageous to improve the fire retardancy of the corresponding nanosol coatings. For example, Vasiljević et al. has prepared nanosol coatings by acidic hydrolysis of the trialkoxysilane containing diphenylphosphorylamino substituent thereby allowing for evaluation of the phosphorus-nitrogen-silicon synergism. ${ }^{10}$ Alongi et al. used diethylphosphato terminated triethoxysilane as a fire retardant for sol-gel coating solutions which were additionally impregnated with 1-hydroxyethane 1,1-diphosphonic acid, melamine and urea affording to estimate the synergetic effectiveness of the additives. ${ }^{11}$ Alumina particles of 50 and 325 nm were also incorporated into silica coatings and subsequently applied onto cotton and cottonlinen blends resulting in improved retention of char in $400-600{ }^{\circ} \mathrm{C}$ temperature range. ${ }^{12}$

In the present paper we present the approach based on treatment of cellulosic textile material with phosphorus-doped silica coatings. Organophosporus fire retardant, 10-(2-trimethoxysilylethyl)-9-hydro-9-oxa-10-phosphaphenanthrene-10-oxide (DOPO-VTS) was synthesized and covalently incorporated into the sol-gel framework by co-hydrolysis co-condensation with tetraethoxysilane (TEOS) precursor. It has been shown from TGA-MS, XPS and flammability tests that the DOPO-VTS coatings act as a char promoting fire retardant via solid phase mechanism. 


\section{Materials and methods}

All chemicals were purchased from Sigma-Aldrich unless otherwise stated. Ethanol (99.9\%), toluene (99.9\%) and water (Milli-Q, $18 \mathrm{M} \Omega \mathrm{cm}$ ) were used as solvents. 9,10-Dihydro-9-oxa-10phosphaphenanthrene-10-oxide (DOPO, >97\%) was supplied by TCI America. Vinyltrimethoxysilane (VTS, 98\%), tetraethyl orthosilicate (TEOS, 99\%), 2,2'-azodiisobutyronitrile (AIBN, 98\%) and sodium dodecyl sulfate (SDS, 95\%) were used as received. Commerciallybleached cotton fabrics with a density of $185 \pm 7 \mathrm{~g} / \mathrm{m}^{2}$ was supplied by Kemotextil A/S.

2.1. Synthesis of 10-(2-trimethoxysilyl-ethyl)-9-hydro-9-oxa-10-phosphaphenanthrene-10oxide (DOPO-VTS). Organophosphorus containing silane was synthesized by the procedure adopted from Zhang et al. ${ }^{13}$ with slight modifications (Scheme 1). Prior to synthesis DOPO was dried under vacuum at $80{ }^{\circ} \mathrm{C}$ for $16 \mathrm{~h}$ and VTS was bubbled with Ar for $0.5 \mathrm{~h}$. To the mixture of $44.6 \mathrm{~g}(200 \mathrm{mmol})$ of DOPO and $32 \mathrm{ml}(205 \mathrm{mmol})$ of VTS in $120 \mathrm{ml}$ of dry toluene, $0.64 \mathrm{~g} \mathrm{(4}$ mmol) of AIBN in $50 \mathrm{ml}$ of toluene was added dropwise within $4 \mathrm{~h}$ at $80{ }^{\circ} \mathrm{C}$. Reaction continued for additional $16 \mathrm{~h}$ at $80{ }^{\circ} \mathrm{C}$ followed by removal of the solvent. The product was dried for $20 \mathrm{~h}$ under vacuum at $80{ }^{\circ} \mathrm{C}$ resulting in viscous colorless oil, yield $94 \%$. The ${ }^{1} \mathrm{H},{ }^{13} \mathrm{C}$ and ${ }^{31} \mathrm{P}$ NMR spectra are presented in the Supporting Information (SI1).

2.2. Preparation of the coating solutions. In all cases the molar ratio between the DOPO-VTS and TEOS silane precursors were fixed to 2:1. As an example, for preparation of 17 wt.\% DOPOVTS/TEOS nanosol coating solution (further abbreviated as $\mathrm{P}+\mathrm{SiO}_{2}$ ), $6.85 \mathrm{~g}$ of DOPO-VTS (18.8 mmol) and $2.1 \mathrm{~mL}(9.4 \mathrm{mmol})$ of TEOS were added to a mixture of $0.01 \mathrm{M} \mathrm{HCl}(17 \mathrm{ml})$ and ethanol $(33 \mathrm{ml}) .{ }^{14}$ The reaction mixture was stirred for $16 \mathrm{~h}$ at room temperature resulting in a viscous turbid nanosol solution. The same co-hydrolysis co-condensation procedure was used for preparation of the nanosol coatings with varying wt.\% of the silane precursors as well as for preparation of the TEOS based nanosol coatings (abbreviated as $\mathrm{SiO}_{2}$ ), Scheme 1. In order to 
produce only organophosporus containing coatings $(\mathrm{P})$ needed for comparison with $\mathrm{SiO}_{2}$ and $\mathrm{P}+\mathrm{SiO}_{2}$ containing coatings, cotton samples were impregnated with 10 wt.\% solution of DOPO in methanol followed by drying at $120^{\circ} \mathrm{C}$ for $1 \mathrm{~h}$.

2.3. Treatment of the fabric with nanosol coatings. The pieces of cotton fabrics were immersed in nanosol solutions of varied concentrations. After 5 minutes of soaking the samples were air-dried for 1 hour at room temperature and cured at $120{ }^{\circ} \mathrm{C}$ for another 1 hour. In order to determine total dry solids add-on on the cotton fabric, each sample was weighted before $\left(W_{\mathrm{b}}\right)$ and after $\left(W_{\mathrm{a}}\right)$ the impregnation with nanosol solution and subsequent curing. Equation 1 was used to calculate the total add-on (A) on cotton fabrics in wt.\% (see Tables 1 and 2).

$$
A=100 \times\left(W_{\mathrm{b}}-W_{\mathrm{a}}\right) / W_{\mathrm{a}}
$$

2.4. Washing of the nanosol treated fabric. In order to remove any physisorbed fire retardant species, $\mathrm{P}+\mathrm{SiO}_{2}$ impregnated fabric was immersed in $10 \mathrm{mM}$ solution of sodium dodecyl sulfate (SDS) and stirred for $16 \mathrm{~h}$ at $60^{\circ} \mathrm{C}$. After surfactant treatment the samples were sonicated 3 times in water and 3 times in ethanol followed by drying at $120^{\circ} \mathrm{C}$ for $1 \mathrm{~h}$.

2.5. X-ray photoelectron spectroscopy. XPS spectra were acquired on ThermoScientific XPS (USA) instrument equipped with Al K-Alpha source of $1486 \mathrm{eV}$ energy. Samples were analyzed using automatic height adjustment and charge compensation by a flood gun in a vacuum not exceeding 2e-7 mbar. X-ray gun spot size was set to the value 400 x $400 \mu$ m. Typically 3 scans were averaged for both survey and high resolution (HR) spectra.

2.6. Thermogravimetric analysis. TGA was performed on all samples on a Netzsch STA 409 CD Thermobalance (Germany). TGA curves were acquired from 23 to $800{ }^{\circ} \mathrm{C}$ using 5 min dwell time, $10{ }^{\circ} \mathrm{C} /$ minute heat rate, in air, at a gas flow equal to $25 \mathrm{ml} / \mathrm{min}$. MS spectra of the decomposition gases were acquired every $1 \mathrm{~min}$ for the $\mathrm{M} / \mathrm{Z}$ values ranging from 1 to 299 g/mole/charge. To determine the temperature at which the decomposition rate acquires local 
maximum ( $T_{\max }$ ) TGA curves were converted to differential thermogravimetric curves (DTGA) by differentiation in Origin 9.0 software (Supporting Information, SI2).

2.7. Scanning electron microscopy. SEM images were acquired on FEI Quanta 200 ESEM FEG (USA) in high vacuum mode (1e-6 mbar) at $5 \mathrm{kV}$ acquisition voltage using Everhart-Thornley secondary electron detector. All samples were covered with less than $10 \mathrm{~nm}$ gold layer prior to every measurement. Also, the stigmation and lens alignment was manually adjusted before image acquisition.

2.8. Vertical flammability test. The flammability of the vertically oriented textile cotton fabric was measured according to EN ISO 15025:2008 standard method. A specimen of size 20 x $16 \mathrm{~cm}$ was first cut out with the help of a standard template. The test specimens were conditioned in an atmosphere having a temperature of $20 \pm 2{ }^{\circ} \mathrm{C}$ and a relative humidity of $65 \pm 5 \%$ for 24 hours. This specimen was then mounted on a rectangular metal frame having a specimen support pin at

each corner. The fire test was performed at room temperature $\left(22 \pm 2{ }^{\circ} \mathrm{C}\right), 26 \pm 5 \%$ relative humidity and air movement less than $0.2 \mathrm{~m} / \mathrm{s}$. The position of the tip of the burner from the surface of the specimen was fixed at a distance of $17 \pm 1 \mathrm{~mm}$. The burner was preheated for 2 minutes and the horizontal length of the flame (from tip of the flame to tip of the burner) from butane gas was adjusted to $25 \pm 2 \mathrm{~mm}$. During the ignition step the flame was applied for $10 \mathrm{~s}$ to the surface of the specimen.

\section{Results and Discussion}

3.1. Concentration of the nanosol coating solution. The results are presented as wt. $\%$ of the nanosol coating grafted to the textile as a function of the wt.\% of the precursors in the coating solution. As evidenced by Figure 1 there is a direct proportionality between the wt.\% of nanosol in solution and solid add-on on the surface. However, the proportionality coefficient is two times 
higher for $\mathrm{P}+\mathrm{SiO}_{2}$ coatings. As observed experimentally, lower solubility of the hydrolyzed DOPOVTS in water/ethanol media results in the formation of turbid and more viscous coating solutions which accounts for twice higher loading of the $\mathrm{P}+\mathrm{SiO}_{2}$ coatings compared to pure $\mathrm{SiO}_{2}$ coatings. However, we do not exclude the possibility that the difference in molecular weight of the silane precursors used may also affect the final loading. Thus, the loading of the fire retardant into the textile material can be conveniently predicted and adjusted by varying the concentration of the silanes in the solution.

3.2. Surface composition of the nanosol coated textiles. High resolution (HR) XPS spectra of $\mathrm{P}+\mathrm{SiO}_{2}$ nanosol coatings were acquired for carbon (C1s), oxygen (O1s) and phosphorus (P2p) elements. From Figure 2A, C1s spectrum of the untreated cotton reveals a major component centered at $287.0 \mathrm{eV}$ which originates from $\mathrm{C}-\mathrm{OH}$ carbon of the cellulose of the cotton. The appearance of the minor peaks at 285 and $288.4 \mathrm{eV}$ indicates the presence of the waxes (aliphatic C) and pectin $(-\mathrm{COOH})$ on the surface of the cotton fibers (Figure 2A). ${ }^{15}$ Upon depositing $\mathrm{P}+\mathrm{SiO}_{2}$ coatings the major carbon peak appears at a lower binding energy ( $284.5 \mathrm{eV})$ which is characteristic for $\mathrm{sp}^{2}$ hybridized carbon (Figure 2D). ${ }^{16}$ It confirms the presence of aromatic biphenyl substituents constituting the DOPO-VTS molecule. In addition, both oxygen peaks appear at lower binding energy upon deposition of the nanosol which can be attributed to the lower induced positive charge of the Si-O- oxygen in the nanosol compared to the C-O- oxygen in the cotton (Figure $2 \mathrm{~B}$ and E). As expected, untreated cotton does not contain any traces of phosphorus, while for DOPO-VTS treated fabric the intense P2p peak appears at $133.1 \mathrm{eV}$ which corresponds to the presence of phosphaphenanthreneoxide moiety. 
In addition, XPS survey spectra were acquired before and after washing of the $\mathrm{P}+\mathrm{SiO}_{2}$ impregnated cotton with SDS solution for $16 \mathrm{~h}$ at $60{ }^{\circ} \mathrm{C}$ to conceptually demonstrate that phosphorus remains in the nanosol coatings even after prolonged surfactant treatment. As expected, the atomic composition of the coatings differs from the composition of the untreated cotton due to the presence of additional $\mathrm{Si}$ and $\mathrm{P}$ elements in the coating formulation. Moreover, the atomic composition is on average constant for the chosen concentration range of the nanosol solutions. Before treatment with SDS all $\mathrm{P}+\mathrm{SiO}_{2}$ coatings on average contained 59 At.\% of carbon, 29 At.\% of oxygen, 10 At.\% of the silicon and 2 At.\% of phosphorus (Figure 3). The theoretical ratio of P/Si is $2 / 3$ considering $2 / 1$ molar ratio of DOPO-VTS/TEOS in the coating solution, while the experimental P/Si ratio is equal to 1/5 (2 At.\% / 10 At.\%). Therefore, the amount of DOPO-VTS incorporated into the nanosol is 3.3 times lower than theoretically expected. It can presumably be explained by the lower tendency of the DOPO-VTS to be incorporated into the poly(DOPO-VTSco-TEOS) copolymer type network due to the steric hindrance caused by bulky organophosphorus substituent.

The thickness of all nanosol coatings is higher than $10 \mathrm{~nm}$ as deducted from the fact that the elemental composition of the nanosol coatings remains constant for all range of nanosol concentrations, i.e., no influence of the underlying cotton on the atomic composition of the upper layer is observed. The statement is based on the fact that maximum analysis depth of the XPS technique is $10 \mathrm{~nm}^{17}$

After SDS treatment the elemental composition have remained primarily unchanged except for the slight increase in the carbon At.\% and decrease in silicon At.\% (Figure 3, open symbols). It is thought to be caused by the partial removal of the loosely bound $\mathrm{SiO}_{2}$ particles which results in exposing the carbon rich poly(DOPO-VTS-co-TEOS) layer. Also, in some instances the data on Figure 3 demonstrate identical amounts of $\mathrm{P}$ before and after washing because the values of filled 
triangles (pointed down, blue colored) are overlapping with the values of the open triangles (pointed down, blue colored).

Since SDS treatment affected the carbon and silicon content in the nanosol coatings further wash tests were not performed on nanosol impregnated substrates. It implies that the composition of the coatings was governed only by the initial composition of the nanosol coating solutions. The latter parameter was always well-defined and therefore the elemental composition of fire retardant coatings remained largely unchanged for all range of concentrations used.

3.3. TGA-MS of the nanosol coatings. TGA curves of the samples containing comparable amount of nanosol coatings with and without organophosphorus fire retardant are presented in Figure 4. The onset decomposition temperatures corresponding to the weight loss of $5 \%\left(T_{5 \%}\right)$ and $10 \%\left(T_{10 \%}\right)$ as well as temperatures at which the decomposition rate acquires local maximum ( $\left.T_{\max 1}, T_{\max 2}, T_{\max 3}\right)$ are summarized in Table 1 . In all cases negligible weight loss occurs at 80-90 ${ }^{\circ} \mathrm{C}\left(T_{\max 1}\right)$ which corresponds to water removal from both untreated and nanosol treated cotton. Furthermore, the presence of phosphorus in the nanosol formulation results in a decrease in the onset of thermal decomposition of cotton by $10-20{ }^{\circ} \mathrm{C}$ and $30-50{ }^{\circ} \mathrm{C}$ for $5 \%$ and $10 \%$ weight loss compared to bare cotton (samples A1-A4, Table 1). At the same time the onset of decomposition for the $\mathrm{SiO}_{2}$ coated cotton did not change significantly since $T_{5 \%}$ and $T_{10 \%}$ have only declined by 1-10 and $13-14{ }^{\circ} \mathrm{C}$ respectively compared to the bare cotton (samples B1-B3).

The decrease of the decomposition temperature of cotton for the phosphorus rich coatings clearly demonstrates the catalytic action of the DOPO-VTS component of the nanosol on the decomposition of cotton. At elevated temperature labile P-C bonds (264 kJ/mol) of the DOPO-VTS cleave thereby releasing acidic intermediates and phosphoric acid which act as a catalyst for further charring of the cotton material. ${ }^{18}$ The charring process is brought about by numerous phosphorylation and dehydration reactions which block the depolymerization of cellulose via the 
formation of flammable levoglucosan species. ${ }^{10,11,19}$ Hence, instead of complete combustion, the cotton is converted to the carbonaceous char starting from $270{ }^{\circ} \mathrm{C}$. The charring process results in the retention of a significantly higher mass of the material in contrast to the untreated or $\mathrm{SiO}_{2}$ coated cotton which otherwise would have been lost via gaseous $\mathrm{CO}_{2}$ and $\mathrm{H}_{2} \mathrm{O}$ decomposition products. Indeed, the residual weight of the $\mathrm{P}+\mathrm{SiO}_{2}$ coated samples is $4-7$ wt.\% higher at $500{ }^{\circ} \mathrm{C}$ compared to only $\mathrm{SiO}_{2}$ coated cotton (Table 1).

As for the pure DOPO treated sample (C1, Table 1), which does not contain silica, its decomposition starts $40^{\circ} \mathrm{C}$ earlier compared to the untreated cotton. Even though a similar amount of char was formed at $500{ }^{\circ} \mathrm{C}$ for the sample C1 when compared to the sample A3, which is 32 wt.\%, the char starts to be oxidized to volatile products after $500{ }^{\circ} \mathrm{C}$ (Figure $4 \mathrm{~B}$ ) resulting in almost complete decomposition of the sample at $800^{\circ} \mathrm{C}$, as evidenced by only $1 \%$ of the weight remaining at this temperature. Such phenomenon confirms the importance of the combination of Si and P elements in the nanosol coatings and indicates the synergetic effect of these two elements with respect to increase in the thermal stability of the char formed from cotton material. ${ }^{20}$

Also, it has been observed (see Supporting Information, SI3) that the char is black colored even after being heated to $800{ }^{\circ} \mathrm{C}$ in the case of $\mathrm{P}+\mathrm{SiO}_{2}$ coated cotton while the char is white resembling pure silica for $\mathrm{SiO}_{2}$ coated cotton. The black color of char provides an indirect evidence of the high carbon content in the char residue (see the discussion below).

From TGA-MS presented in Figure 5 it is evident that the evolution of the $\mathrm{CO}_{2}$ occurs in tree steps corresponding to usually observed degradation pattern of the nanosol coated cotton, namely 300-400 ${ }^{\circ} \mathrm{C}$ (I), 400-600 ${ }^{\circ} \mathrm{C}$ (II) and $600-800{ }^{\circ} \mathrm{C}$ (III). ${ }^{12}$ These steps delimit the gradual transformation of cotton to aliphatic (I) and aromatic (II) char as well as complete oxidation of the aromatic char to volatile products (III). For the loading of the organophosphorus higher than 20 
wt.\% (samples A4 and C1) a significant amount of $\mathrm{CO}_{2}$ is released in $600-800{ }^{\circ} \mathrm{C}$ temperature range while the untreated cotton evolves most of the $\mathrm{CO}_{2}$ below $650{ }^{\circ} \mathrm{C}$. As long as TEOS coated samples are concerned (B1-B3), identical degradation pattern was identified: they all loose carbon in the form of $\mathrm{CO}_{2}$ at relatively low temperatures $\left(300-600{ }^{\circ} \mathrm{C}\right)$. Thus TGA-MS spectra additionally corroborate that the oxidation of the char is delayed for the DOPO-VTS and DOPO containing samples.

3.4. SEM of the char residues of the nanosol coatings. Further confirmation of the importance of the $\mathrm{P}+\mathrm{SiO}_{2}$ combination is obtained though analysis of the char residuals of the samples after TGA. Two cotton samples coated with 35 wt.\% of $\mathrm{P}+\mathrm{SiO}_{2}$ (A3) and 35 wt.\% of the $\mathrm{SiO}_{2}$ (B3) were analyzed by SEM before and after being heated to $800{ }^{\circ} \mathrm{C}$ in air. The appearance of the samples before thermal degradation is quite similar - they both demonstrate fibrillose structures homogenously coated with nanosol films (Figure 6). The degradation of A3 leads to the merging of the fibrils and the formation of the homogeneous char layer while the initial structure of the material is more or less preserved for the thermally decomposed sample B3. The formation of the homogeneous char layer for the sample A3 was ascribed to the occurrence of the crosslinking reactions catalyzed by phosphoric acid and phosphorus pentoxide released during the thermal degradation of the $\mathrm{P}+\mathrm{SiO}_{2}$ coated cotton. ${ }^{21}$ The formation of the homogeneous char layer points to the fact that the fire retardant acts by a solid phase mechanism, which is in a good agreement with TGA-MS data. Furthermore it also means that the fire retardant is potentially capable of preventing further degradation of the material due to barrier properties of the compact char. ${ }^{22}$

On the other hand, the initial structure of the fibers is apparently preserved when no phosphorus was present during the thermal degradation of the $\mathrm{SiO}_{2}$ coated cotton. The retention of the initial 
shape of the cotton fibers stems from the high thermal stability of the $\mathrm{SiO}_{2}$ inorganic coatings, which are known to be stable up to $1000{ }^{\circ} \mathrm{C}$. In addition, from optical microscope imaging (see Supporting Information, SI3) the white color and brittleness of the TGA residue of the sample B3 indicates that it is mainly composed of inorganic material $\left(\mathrm{SiO}_{2}\right)$. The residue from sample $\mathrm{A} 3 \mathrm{is}$, in contrast, black colored due to high content of the carbonaceous residue.

3.5. Vertical flammability of the nanosol coatings. In order to assess the flammability of the coatings $20 \times 16 \mathrm{~cm}$ cotton samples treated with $\mathrm{P}+\mathrm{SiO}_{2}$ and $\mathrm{SiO}_{2}$ were subjected to the standard vertical flammability test (EN ISO 15025:2008). At low loading of the nanosol (1-5 wt.\%) the reduction in the flammability is similar for both $\mathrm{P}+\mathrm{SiO}_{2}$ and $\mathrm{SiO}_{2}$ coatings, that is, burn rate decreased by $31-54 \%$. Rather high loading of the $\mathrm{P}+\mathrm{SiO}_{2}$ nanosol was needed in order to decrease the burn rate by $89 \%$ (Table 2). At high loading of the $\mathrm{SiO}_{2}$ nanosol (17 wt.\%) the decrease in the burn rate was $54 \%$. Since samples A7 and B7 have different fire retardant loads, their direct comparison with respect to efficiency of $\mathrm{P}+\mathrm{SiO}_{2}$ and $\mathrm{SiO}_{2}$ coatings is not realized in the present work.

Regarding charring process, the amount of char increases from less than $0.1 \mathrm{wt} . \%$ for pure cotton to 26 wt.\% for $\mathrm{P}+\mathrm{SiO}_{2}$ treated cotton (A7). A similar trend was observed for $\mathrm{SiO}_{2}$ treated samples (B5-B7), which confirms that both $\mathrm{P}+\mathrm{SiO}_{2}$ and $\mathrm{SiO}_{2}$ fire retardants act thought an additive effect in the condensed phase.

It is known, that there are two processes, namely pyrolysis and combustion, involved when a fuel material (textile) catches fire. Pyrolysis is the first process during the course of fire that involves thermal decomposition of cellulose into combustible volatiles, inert gases and a solid residue (char). Combustion is the second process involving oxidation of combustible volatiles (gases) and 
formation of a flame (fast oxidation). The char smoldering or glow (slow oxidation) may or may not occur depending on the mechanism of action of a given fire retardant. ${ }^{23}$

Even though similar char residues were found for $\mathrm{P}+\mathrm{SiO}_{2}$ and $\mathrm{SiO}_{2}$ treated cotton, an important difference between organophosporus and silica based fire retardant was identified during the flammability test. The smoldering of $\mathrm{SiO}_{2}$ treated cotton samples occurred every time after the fabric was ignited. On contrary, smoldering was not typical for $\mathrm{P}+\mathrm{SiO}_{2}$ containing samples. Since smoldering results in a gradual oxidation of the carbon by the oxygen diffusing though the inorganic silica coatings, it is reasonable to assume that the char will contain less carbon for the silica treated samples compared to $\mathrm{P}+\mathrm{SiO}_{2}$ treated ones. Indeed, from elemental composition of the char residues presented in Table 2 it follows that carbon content increase steadily with the increase in the loading of organophosporus fire retardant. Silica coated cotton shows an opposite trend progressively lower amount of carbon remains for higher silica loadings which is in agreement with slow burning out of the carbon from silica treated samples during the smoldering phenomenon. Hence the smoldering was enhanced by the purely inorganic $\mathrm{SiO}_{2}$ coatings and suppressed by phosphorus containing fire retardant coatings. Overall, the synthesized $\mathrm{P}+\mathrm{SiO}_{2}$ coatings operate in a condensed phase during the pyrolysis process.

Noteworthy, from Table 2 it follows that the amount of char is comparable for the samples A7 and B7 (26 and 22 wt.\%) even though the loading of the fire retardant is lower for B7 (17 wt.\%) than for A7 (23 wt.\%). However, values of C1s At.\% clearly indicate that the char contains more carbon in the case of sample A7 (58.5 At.\%) than in the case of sample B7 (10.9 At.\%), i.e., the char produced from sample A7 is carbonaceous-siliceous, while the char produced from sample B7 is primarily siliceous. Thus, the findings from flammability test and XPS quantification results are in a good agreement with TGA (Figure 4) as well as optical microscope imaging data (Supporting 
Information, SI3) with respect to the retention of higher amount of carbon by phosphorus containing silica coatings.

3.6. Mechanism of action of DOPO-VTS. From TGA-MS and XPS data we proposed the mechanism for the stepwise degradation of the cotton material in the presence of DOPOVTS/TEOS fire retardant coatings (Scheme 2). When applied to cotton, the mechanism of action of DOPO and DOPO-VTS fire retardants changes from the postulated gas phase ${ }^{24}$ to exclusively solid phase. The cotton treated with DOPO-VTS or DOPO does not evolve gaseous species corresponding to the decomposition products of DOPO, namely oxophosphine and dibenzofuran (see Supporting Information, SI4). Instead, phosphorylation of C(6) hydroxyl groups, dehydration and crosslinking of the cotton take place within $300-400{ }^{\circ} \mathrm{C}$ temperature resulting in formation of the aliphatic char (Scheme 2). ${ }^{25,26}$ The degradation reactions are accompanied by evolution of furan derivatives, ketones and aldehydes which were identified by TGA-MS in $300-400{ }^{\circ} \mathrm{C}$ temperature range in the present work (Supporting Information, SI4) and are in agreement with the products of cotton decomposition reported by Lin Y.-C et al. ${ }^{27}$

Second, the formation of $-\mathrm{P}(=\mathrm{O})-\mathrm{O}-\mathrm{Si}-\mathrm{O}-$ linkages $^{20}$ and aromatization ${ }^{25}$ takes place at $400-600$ ${ }^{\circ} \mathrm{C}$. The formed carbonaceous-siliceous aromatic char precludes complete combustion of the cotton material which accounts for the high carbon content in the char residues observed by XPS. Indeed, as much as 58 At.\% of carbon was detected by XPS in the char residues produced after the flammability test performed on sample A7 (Table 2). Moreover, from HR XPS analysis (Supporting Information, SI5) of the char residuals we observed shift of the binding energy for P2p and Si2p peaks to on average $1 \mathrm{eV}$ higher values indicating the increase in the oxidation state and/or the magnitude of the induced positive charge on those elements. ${ }^{28}$ This finding gives support to the direct binding of phosphate group to silicon atoms and is in agreement with the proposed mechanism of carbonaceous-siliceous char formation (Scheme 2). 


\section{Conclusions}

The results indicate that the presence of organophosphorus fire retardant in the silica-based nanosol coatings is capable of enhancing the fire retardant properties of the cotton textile treated with such formulation. At temperature above $500{ }^{\circ} \mathrm{C}$ only $\mathrm{SiO}_{2}$ or only $\mathrm{P}$ containing coatings were unable to produce the amount of char equivalent to $\mathrm{P}+\mathrm{SiO}_{2}$ coatings. Synergetic effect stemming from the combination of $\mathrm{Si}$ and P elements was further manifested in up to $89 \%$ reduction of the burn rate of cotton treated with $\mathrm{P}+\mathrm{SiO}_{2}$ formulation compared to untreated cotton. Moreover, $\mathrm{P}+\mathrm{SiO}_{2}$ coatings conferred the absence of smoldering on cotton also. However, better flame retardant behavior was only achieved with the highest load of phosphorus-doped silica coatings (23 wt.\%) which was higher than the load of pure silica (17 wt.\%). For this reason a thorough comparison between the highest loads of the fire retardant coatings could not be made, under these conditions.

\section{Acknowledgements}

Authors Kristoffer Almdal and Sergey Chernyy are thankful to The Danish National Advanced Technology Foundation for the financial support of the Safe Flame Retardants (SRF) project.

\section{Supporting Information}

NMR spectra, HR XPS scans, DTGA, optical microscope images and TGA-MS curves are grouped in the Supporting Information. This material is available free of charge via the Internet.

\section{References}

1. Horrocks, A. R. In Textile Finishing; Heywood, D., Ed.; Society of Dyers and Colourists: West Yorkshire, UK, 2003.

2. $\quad$ Lam, Y.-L.; Kan, C.-W.; Yuen, C.-W. M., Textile Progress 44, 1752012. 
3. $\quad$ Price, D.; Anthony, G.; Carty, P. In Fire Retardant Materials; Horrocks, A. R.; Price, D., Eds.; Woodhead Publishing, 2001.

4. $\quad$ Ni, J.; Tai, Q.; Lu, H.; Hu, Y.; Song, L., Polym. Adv. Technol. 21, 3922010.

5. $\quad$ Qian, X.; Song, L.; Wang, B.; Hu, Y.; Yuen, R. K. K., Mater. Chem. Phys. 139, 4432013.

6. $\quad$ Camino, G.; Costa, L.; Trossarelli, L., Polym. Degrad. Stab. 6, 2431984.

7. $\quad$ Totolin, V.; Sarmadi, M.; Manolache, S. O.; Denes, F. S., AATCC Review 9, 342009.

8. $\quad$ Totolin, V.; Sarmadi, M.; Manolache, S. O.; Denes, F. S., J. Appl. Polym. Sci. 117, 2812010.

9. $\quad$ Totolin, V.; Sarmadi, M.; Manolache, S. O.; Denes, F. S., J. Appl. Polym. Sci. 124, 1162012.

10. Vasiljević, J.; Hadžić, S.; Jerman, I.; Černe, L.; Tomšič, B.; Medved, J.; Godec, M.; Orel, B.; Simončič, B., Polym. Degrad. Stab. 98, 26022013.

11. Alongi, J.; Colleoni, C.; Rosace, G.; Malucelli, G., Polym. Degrad. Stab. 98, 5792013.

12. Alongi, J.; Malucelli, G., Polym. Degrad. Stab. 98, 14282013.

13. Zhang, W.; Yang, R., J. Appl. Polym. Sci. 122, 33832011.

14. Mahltig, B.; Böttcher, H.; Knittel, D.; Schollmeyer, E., Textile Res. J. 74, 5212004.

15. Chung, C.; Lee, M.; Choe, E. K., Carbohydr. Polym. 58, 4172004.

16. Watts, J. F., Surf. Interface Anal. 20, 2671993.

17. Iruthayaraj, J.; Chernyy, S.; Lillethorup, M.; Ceccato, M.; Røn, T.; Hinge, M.; Kingshott, P.; Besenbacher, F.; Pedersen, S. U.; Daasbjerg, K., Langmuir 27, 10702011.

18. Gaan, S.; Sun, G., J. Anal. Appl. Pyrolysis 78, 3712007.

19. Hendrix, J. E.; Drake, G. L.; Barker, R. H., J. Appl. Polym. Sci. 16, 411972.

20. Zhang, W.; Li, X.; Fan, H.; Yang, R., Polym. Degrad. Stab. 97, 22412012.

21. Cho, C.-S.; Chen, L.-W.; Chiu, Y.-S., Polym. Bull. 41, 451998.

22. Gaan, S.; Sun, G., Polym. Degrad. Stab. 92, 9682007.

23. Shafizadeh, F.; Sekiguchi, Y., Combust. Flame 55, 1711984.

24. Rakotomalala, M.; Wagner, S.; Döring, M., Materials 3, 43002010.

25. Horrocks, A. R. In Fire Retardant Materials; Horrocks, A. R.; Price, D., Eds.; Woodhead Publishing, 2001.

26. Kandola, B. K.; Horrocks, A. R.; Price, D.; Coleman, G. V., J.M.S. - Revs. Macromol. Chem. Phys. C36, 7211996.

27. Lin, Y.-C.; Cho, J.; Tompsett, G. A.; Westmoreland, P. R.; Huber, G. W., J. Phys. Chem. C 113, 200972009.

28. $\quad$ Rupper, P.; Gaan, S.; Salimova, V.; Heuberger, M., J. Anal. Appl. Pyrolysis 87, 932010.

\section{Captions}

Figure 1 . Wt. \% of the nanosol coating on the surface (in relation to the mass of the nanosol plus mass of the textile) versus wt.\% of the silane precursors in the coating solution.

Figure 2. HR XPS spectra of the (A, D) C1s, (B, E) O1s and (C, F) P2p electrons for (A, B, C) non-modified cotton and (D, E, F) cotton containing $35 \mathrm{wt} . \%$ of the DOPO-VTS/TEOS based nanosol. Elemental composition for non-modified cotton: 56.8 At.\% C, 43.2 At.\% O. Elemental composition for cotton containing 35 wt.\% of the DOPO-VTS/TEOS based nanosol: 58.4 At.\% C, 31.3 At.\% O, 8.6 At.\% Si, 1.7 At.\% P. Elemental composition for cotton containing 35 wt.\% of the TEOS based nanosol: 39.8 At.\% C, 42.3 At.\% O, 17.9 At.\% Si. 
Figure 3. At.\% of the elements on a surface of $\mathrm{P}+\mathrm{SiO}_{2}$ coated cotton samples before (filled symbols) and after (open symbols) washing with $10 \mathrm{mM}$ sodium dodecyl sulfate (SDS) solution for $16 \mathrm{~h}$ at $60{ }^{\circ} \mathrm{C}$. The point at 0 wt.\% of the nanosol coating corresponds to the atomic composition of the untreated cotton.

Figure 4. TGA curves of the samples with (A) low ( $<10$ wt.\%) and (B) high ( $>10$ wt.\%) fire retardant loading.

Figure 5. TGA-MS spectra of the $\mathrm{CO}_{2}$ evolution as a function of temperature.

Figure 6. SEM images of the nanosol coated textiles containing (A-H) 35\% of the DOPO-VTS/TEOS (Sample A3) and (I-P) 35\% of TEOS (Sample B3) based nanosol (A-G and I-O) before and (B-H and J-P) after being heated to $800^{\circ} \mathrm{C}$ in air.

Table 1. TGA parameters of the samples coated with DOPO-VTS/TEOS, TEOS and DOPO fire retardants ${ }^{a}$

${ }^{a}$ Cotton textile samples were coated with nanosol based on (A1-A4) DOPO-VTS/TEOS and (B1-B3) TEOS formulations. In addition, sample $\mathrm{C} 1$ was coated by immersing cotton into 10 wt.\% solution of DOPO in methanol followed by drying at $120{ }^{\circ} \mathrm{C}$ for 1h.

Table 2. The data from the vertical flammability test along with elemental composition of the samples before and after flammability test determined by XPS

${ }^{a}$ The normalized burn rate represents the burn rate divided by the mass of the nanosol treated cotton.

${ }^{b}$ The values corresponding to the atomic composition of nanosol treated cotton and char residuals are reported before and after slash separator (/) respectively.

Scheme 1. Synthesis of DOPO-VTS silane precursor and its hydrolytic co-condensation with TEOS in acidic conditions. Condensation of TEOS alone was also performed for a comparison.

Scheme 2. The proposed mechanism of action of the synthesized DOPO-VTS based fire retardant coatings. 
Scheme1

DOPO-VTS/TEOS based nanosol coatings:

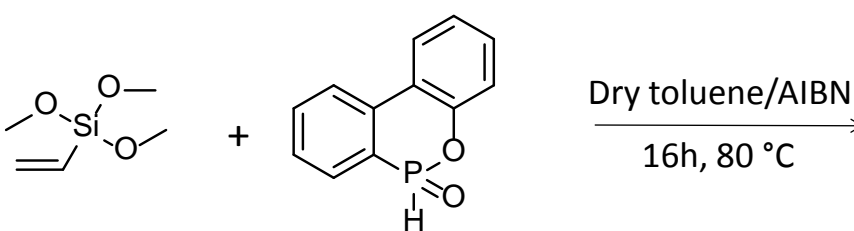<smiles>CO[Si](CCP1(=O)Oc2ccccc2-c2ccccc21)(OC)OC</smiles><smiles>CO[Si](CCP1(=O)Oc2ccccc2-c2ccccc21)(OC)OC</smiles>

DOPO-VTS<smiles>CCO[Si](OCC)(OCC)OCC</smiles>

TEOS

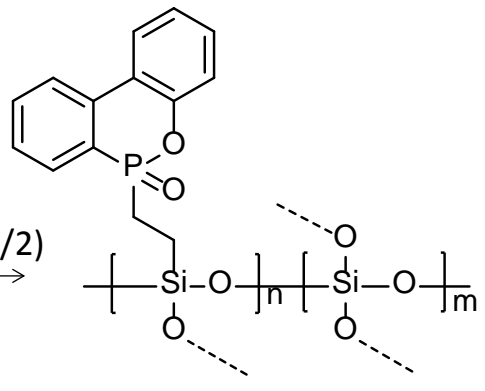

$\underline{\text { TEOS based nanosol coatings: }}$

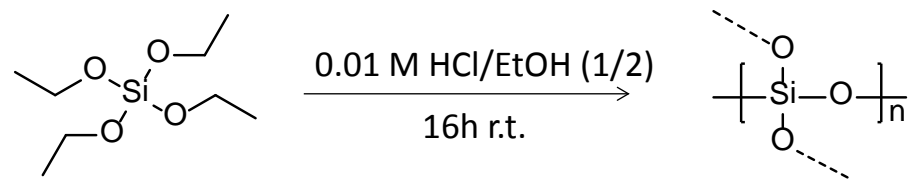

Figure 1

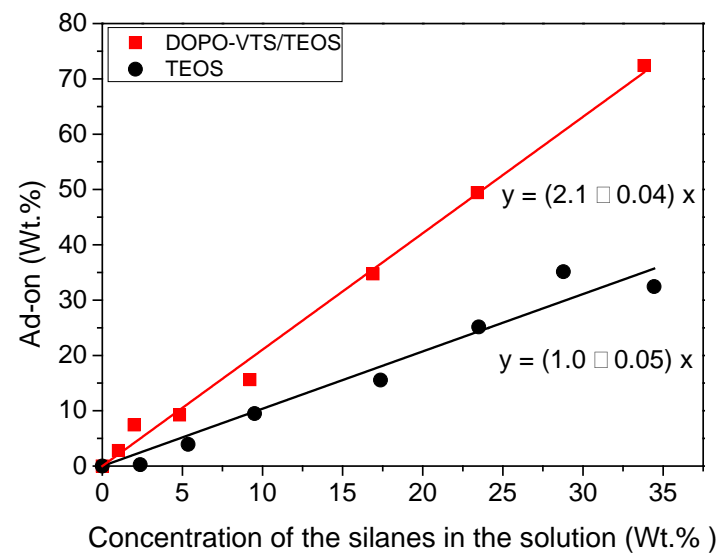

Figure 2 

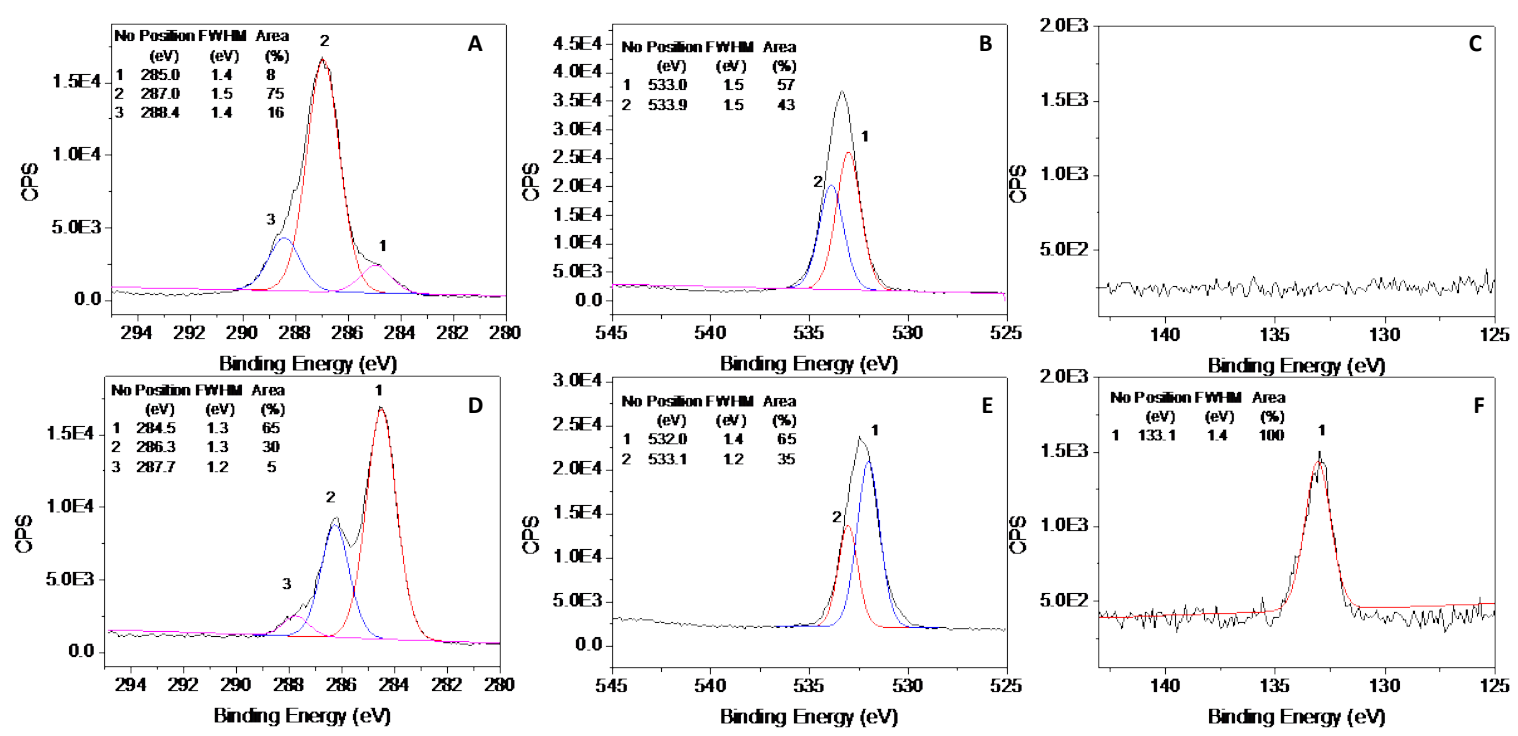

Figure 3

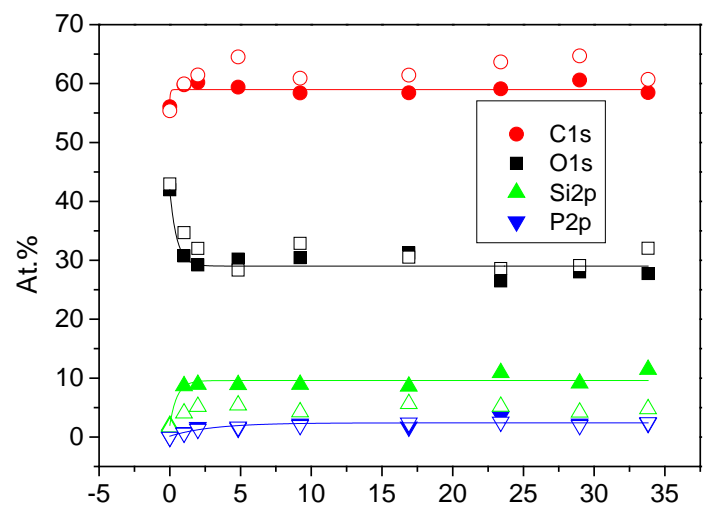

Concentration of DOPO-VTS/TEOS in the solution (wt.\%)

Figure 4
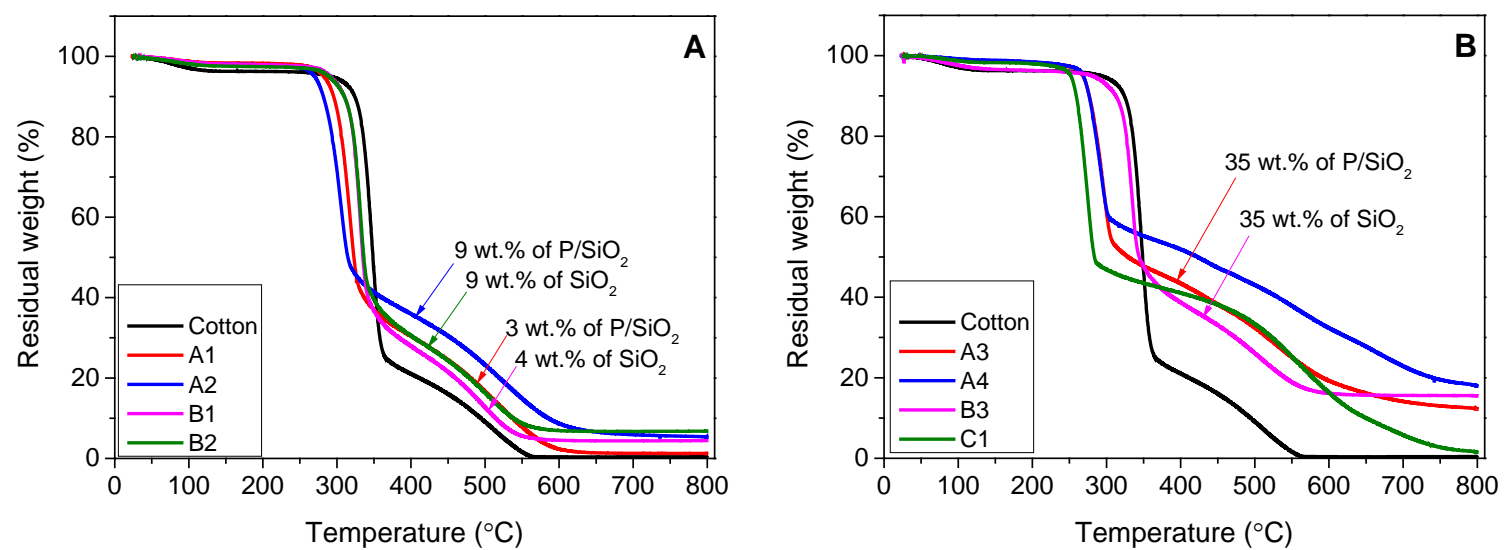

Figure 5 


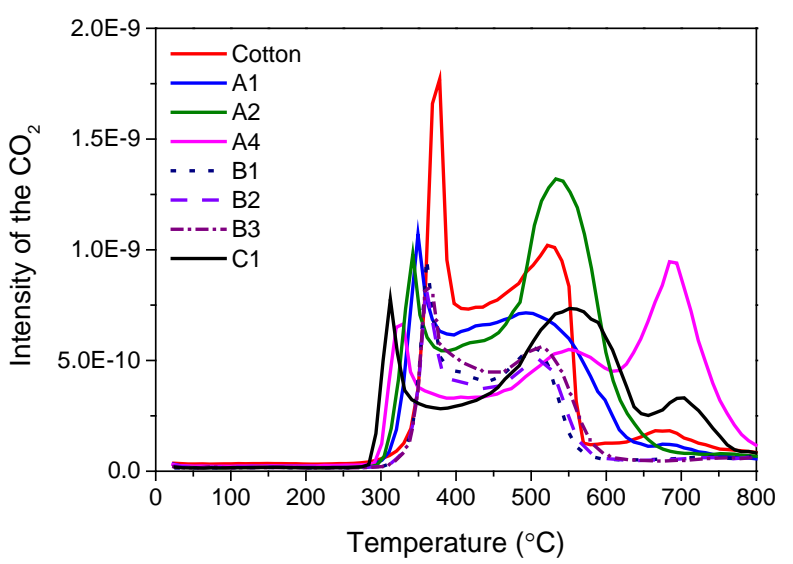

Scheme 2

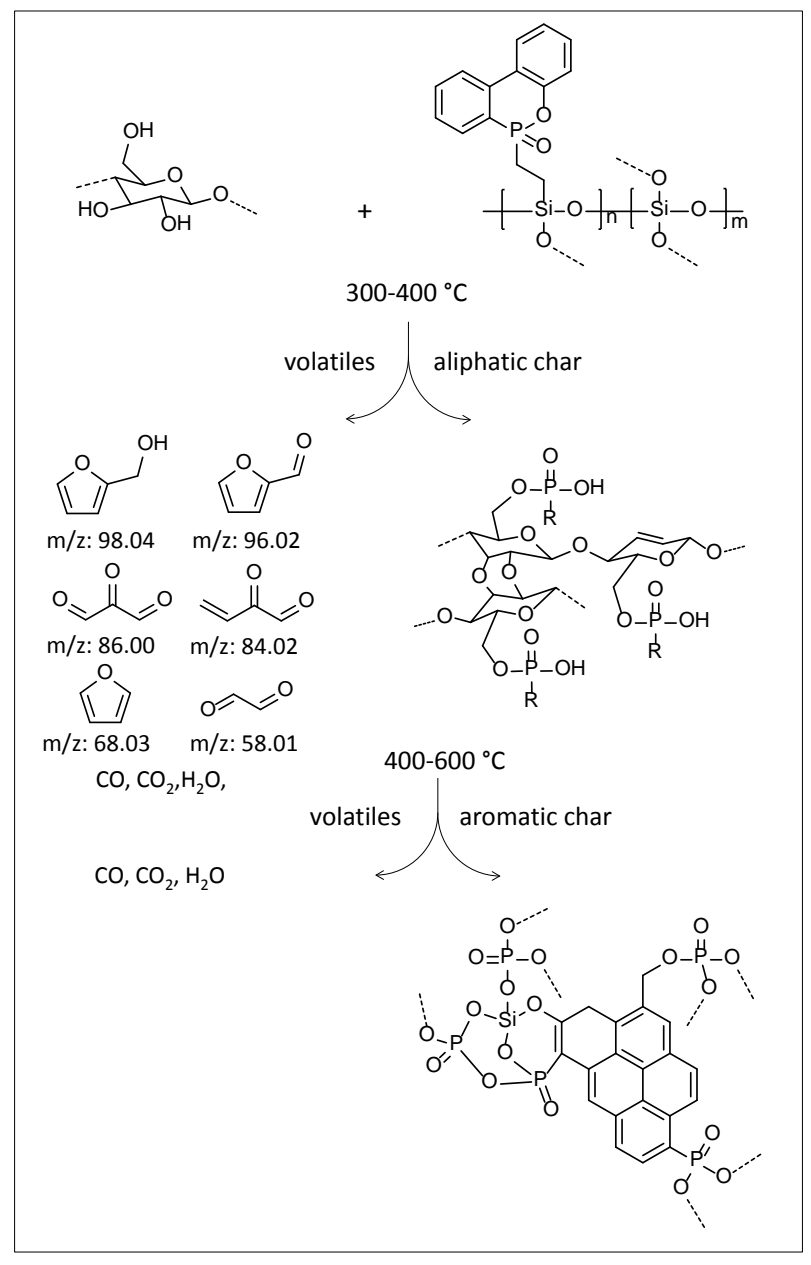

